\title{
Postmyocardial infarction ventricular septal rupture as a potentially fatal complication: when time is the best medicine
}

\author{
Isabel Durães Campos @ (1) 1,2 Eric Bonnefoy-Cudraz, ${ }^{2}$ Matteo Pozzi, ${ }^{3}$ Ahmad Hayek ${ }^{2}$
}

${ }^{1}$ Cardiology Department, Hospital de Braga, Braga, Portugal

${ }^{2}$ Cardiac Intensive Care Unit, Hôpital Cardiologique Louis Pradel, Lyon, France

${ }^{3}$ Cardiovascular Surgery Department, Hôpital Cardiologique Louis Pradel, Lyon, France

\section{Correspondence to}

Dr Isabel Durães Campos; isabelcdcampos@gmail.com

Accepted 26 August 2020

\section{DESCRIPTION}

A 78-year-old man was urgently referred to the Department of Cardiology of our hospital with a ventricular septal rupture (VSR) secondary to a myocardial infarction (MI). Three weeks prior to admission, the patient reported an episode of severe chest pain lasting several hours, with a limiting and progressive dyspnoea on exertion.

On admission, physical examination revealed a pulse rate of 101 beats/min, temperature of $35.7^{\circ} \mathrm{C}$, a respiratory rate of 22 breaths $/ \mathrm{min}$ and blood pressures of $118 / 87 \mathrm{~mm} \mathrm{Hg}$. The cardiac auscultation revealed a harsh holosystolic murmur (grade 4/6), heard throughout the precordium but more audible at the left sternal border, associated with a palpable thrill. The patient also presented a S3 gallop, elevated jugular venous pressure and diminished breath sounds at the right lung base. The ECG showed abnormal Q waves in the leads II, III and $\mathrm{aV}_{\mathrm{F}}$. Transthoracic echocardiography revealed a dilated and dysfunctional left ventricle with akinesia of the basal half of the inferior and posterior wall. We also confirmed the presence of a large $(14 \mathrm{~mm})$, sharply demarcated VSR at the level of the posterobasal septum, with a turbulent left-toright shunt (figure 1 and video 1)-interventricular

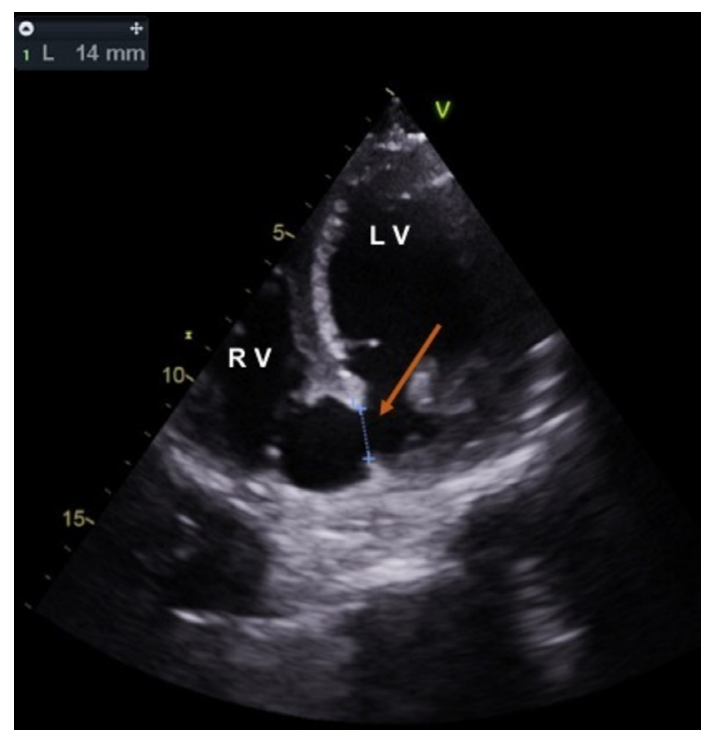

Figure 1 Transthoracic echocardiography, apical 4-chamber view (zoom on the left ventricle), presenting a rupture of the interventricular septum, at the level of the posterobasal septum. LV, left ventricle; RV, right ventricle. Arrow: interventricular septal rupture. pressure gradient $=58 \mathrm{~mm} \mathrm{Hg}$. Given these findings, the patient underwent an urgent cardiac catheterisation which showed a left main and three-vessels disease, with a total occlusion of the mid right coronary artery with collateral supply (figure 2A,B). An intra-aortic balloon pump was placed, and the patient was referred for urgent surgery. The left ventricle was opened through a posterior ventriculotomy after a conventional cardiopulmonary bypass with cardioplegic arrest. The VSR was closed using a Dacron patch, excluding the infarcted area (figure 3). A double coronary artery bypass grafting was also performed.

The patient's postoperative course was uneventful and the echocardiography at hospital discharge showed a satisfactory surgical result without residual VSR. Six months post surgery, the patient remained asymptomatic without hospitalisation for heart failure.

In the era of primary percutaneous coronary intervention, VSR has become an increasingly rare complication of acute MI, although a serious one. ${ }^{1}$ The left anterior descending and right coronary arteries are the most common culprit lesions leading to VSR. ${ }^{2}$ In stable patients, the presence of a murmur or routine echocardiography findings may be the only clues for diagnosis. Our paper is a reminder that despite a recognised poor prognosis, patients can survive surgery without complications. We present an atypical case of a patient referred to our centre with a systolic murmur as the primary reason for consultation, approximatively 3 weeks after the MI, revealing a three-vessel artery disease and a concerning left main artery stenosis, as well as a large VSR. Since the patient's condition can quickly progress to severe heart failure, pulmonary oedema and cardiogenic shock, referral to a tertiary centre with a multidisciplinary Heart Team represents the cornerstone in the management of such patients. Non-surgical management is only a temporary solution and involves afterload reduction with intravenous vasodilators and intra-aortic balloon pump to reduce left-right shunt. Moreover, diuretics could be used to reduce pulmonary congestion and vasopressors in case of circulatory collapse. ${ }^{3}$ Despite a high morbidity and mortality, the best curative treatment is the surgical repair of the VSR. However, the optimal timing remains uncertain and challenging. ${ }^{1}$ Surgery remains the gold standard treatment for post-MI VSR, but more recently, percutaneous closure of VSR emerged as a potential alternative to surgery in selected cases. 


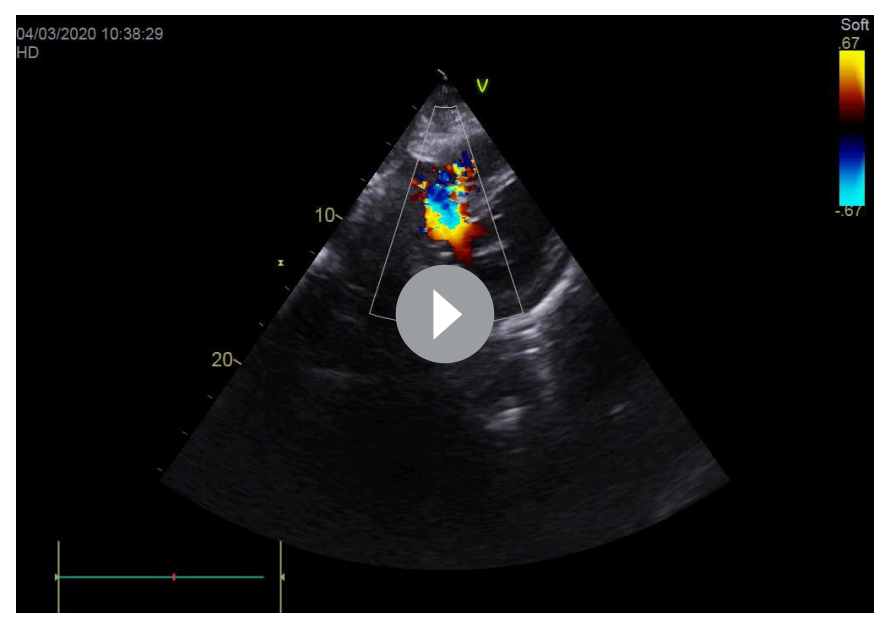

Video 1 Transthoracic echocardiography, subcostal view, revealing a large ventricular septal rupture at the level of the posterobasal septum, with a turbulent left-to-right transseptal flow
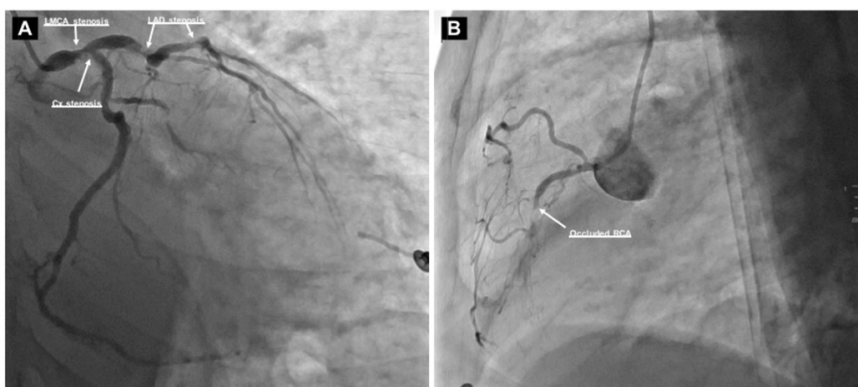

Figure 2 Coronary angiography demonstrating a left main and threevessels disease. (A) Significant left main coronary artery disease ( $>50 \%$ diameter stenosis) with significant stenosis of the proximal and mid segments of the left anterior descending and the proximal segment of the circumflex artery. (B) Balanced coronary system with complete occlusion of the mid segment of the right coronary artery (filled by the heterocollateral circulation). $C x$, circumflex artery; LAD, left anterior descending; LMCA, left main coronary artery; RCA, right coronary artery.

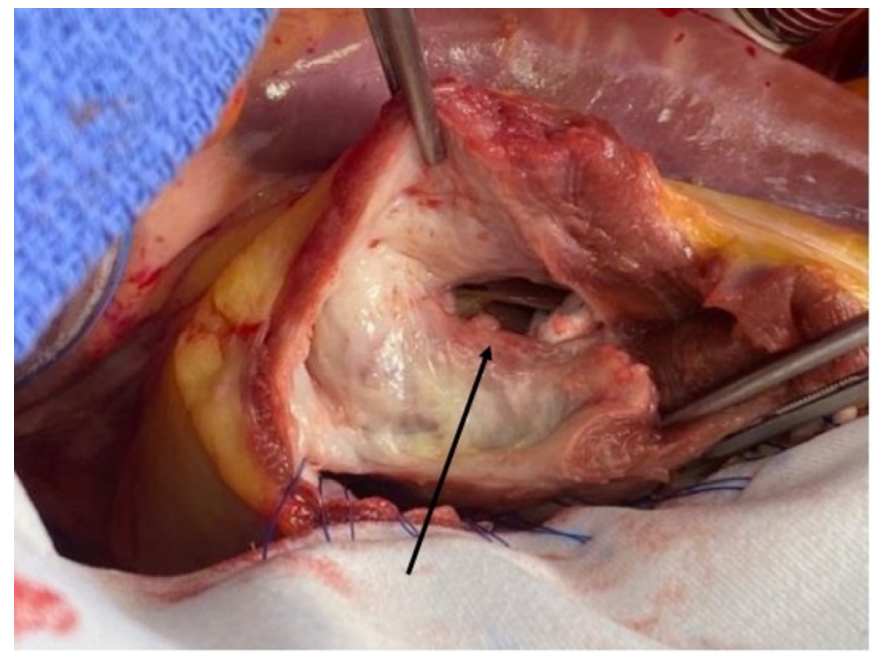

Figure 3 Visualisation of a large ventricular septal rupture at the level of the posterobasal septum. Opening of the left ventricular posterior wall corresponding to the infarction area. Arrow: interventricular septal rupture.
Hence, percutaneous transcatheter septal closure (TSC) has become a valuable alternative in patients with high surgical risk, with a high rate of procedural success $(>75 \%)$, especially in defects $<15 \mathrm{~mm}$, although the mortality rate remains high. ${ }^{4}$ Finally, TSC also plays a role as a rescue therapy for residual defects following initial surgical repair.

Herein, we report a successful case with an uncommon presentation of a mechanical complication of MI, which illustrates the decisive role of clinical examination and the echocardiography in the diagnosis, management and follow-up of VSR.

\section{Learning points}

Ventricular septal rupture (VSR) has become an infrequent but serious complication of acute myocardial infarction (MI) in the era of primary percutaneous coronary intervention. Most commonly, VSR develops within a few days after a transmural MI.

- Clinical examination and echocardiography are pivotal in the diagnosis of VSR. Harsh systolic murmur may be the leading and only clinical sign. Patients can be paucisymptomatic for some time after MI, despite a large VSR and a severe coronary artery disease.

- Despite high morbidity and mortality rates, when possible surgical repair of the VSR remains the gold standard treatment of VSR. Percutaneous transcatheter septal closure has become a valuable alternative in patients with high surgical risk.

Contributors IDC and AH were responsible for medical data acquisition. IDC wrote the manuscript. EB-C and MP were the doctors responsible for the case orientation. AH, EB-C and MP revised the manuscript for important intellectual content. All authors gave the final approval of the version to be published.

Funding The authors have not declared a specific grant for this research from any funding agency in the public, commercial or not-for-profit sectors.

Competing interests None declared.

Patient consent for publication Obtained.

Provenance and peer review Not commissioned; externally peer reviewed.

\section{ORCID iD}

Isabel Durães Campos http://orcid.org/0000-0002-9332-4295

\section{REFERENCES}

1 Liebelt JJ, Yang Y, DeRose JJ, et al. Ventricular septal rupture complicating acute myocardial infarction in the modern era with mechanical circulatory support: a single center observational study. Am J Cardiovasc Dis 2016;6:10-16.

2 Jones BM, Kapadia SR, Smedira NG, et al. Ruptura do septo ventricular que complica 0 infarto agudo do miocárdio: uma revisão contemporânea. Eur Heart J 2014;35:2060-8.

3 Ibanez B, James S, Agewall S, et al. Esc guidelines for the management of acute myocardial infarction in patients presenting with ST-segment elevation: the task force for the management of acute myocardial infarction in patients presenting with ST-segment elevation of the European Society of cardiology (ESC). Eur Heart J 2017;2018:119-77.

4 Schlotter F, de Waha S, Eitel I, et al. Interventional post-myocardial infarction ventricular septal defect closure: a systematic review of current evidence. Eurolntervention 2016;12:94-102. 
Copyright 2020 BMJ Publishing Group. All rights reserved. For permission to reuse any of this content visit https://www.bmj.com/company/products-services/rights-and-licensing/permissions/

BMJ Case Report Fellows may re-use this article for personal use and teaching without any further permission.

Become a Fellow of BMJ Case Reports today and you can:

- Submit as many cases as you like

- Enjoy fast sympathetic peer review and rapid publication of accepted articles

Access all the published articles

Re-use any of the published material for personal use and teaching without further permission

Customer Service

If you have any further queries about your subscription, please contact our customer services team on +44 (0) 2071111105 or via email at support@bmj.com.

Visit casereports.bmj.com for more articles like this and to become a Fellow 